\title{
Chromosome 15 Loss of Heterozygosity
}

National Cancer Institute

\section{Source}

National Cancer Institute. Chromosome 15 Loss of Heterozygosity. NCI Thesaurus. Code C157642.

A molecular abnormality that results in monoallelic loss of function mutations located within chromosome 15. 